\title{
Study on the Impact of Product Harm Crisis Attribution on Brand Stigma
}

\author{
Baocai Fan \\ Business School, Sichuan University \\ Chengdu, Sichuan, P.R. China \\ e-mail: baocaifan@126.com
}

\author{
Hong Wang \\ Business School, Sichuan University \\ Chengdu, Sichuan, P.R. China \\ e-mail: 781617414@qq.com
}

\begin{abstract}
Product harm crisis are frequent, hard to avoid, different to each other, and have various impact. Not all product harm crisis make enterprises brand get bad image and deteriorating stigma. The key elements causing brand stigma by a product harm crisis event lie in brand relationship norms and commitment and brand identification plays a media function. The paper discusses the impact of product harm crisis on brand stigma, explore its conditions and function mechanism and conclude with a conceptual model.
\end{abstract}

Key words: product harm crisis, crisis attribution, brand relationship

\section{INTRODUCTION}

Product harm crisis are frequent, hard to avoid, different to each other, and have various impact. Therefore product harm crisis is of great importance to firms. The marketing literature defines stigma as "a mark placed on a person, place, technology, or product associated with a particular attribute that identifies it as different and deviant, flawed or undesirable" (Kasperson, Jhaveri, \& Kasperson, 2001) and results in elevated risk perceptions.

We have found that brand relationship norms and brand relationship commitment could adjust brand stigma. Compared to ability attribution, morality attribution could cause more serious brand stigma (Aaker, 1991). Under the communal brand relationship norms, morality attribution is easier than ability attribution that cause brand stigma; Brand relationship norms would adjust the influence of crisis attribution on brand stigma. Under the exchange brand relationship norms, ability attribution is easier than morality attribution that cause brand stigma - this hypothesis is not proved.

We are confronting the situation that brand relationship would adjust brand stigma. Under high level brand relationship commitment, the brand stigma that caused by morality attribution and ability attribution perspective is not obvious enough; Under low level brand relationship commitment, morality attribution is easier than ability attribution that cause brand stigma; Brand relationship is able to decrease the level of brand stigma; Brand relationship commitment could adjust the impact of product harm crisis on brand stigma.

Similarly, we have found that brand identification plays a media function role (Bearden, 1983). Brand identification has media function that product harm crisis at- tribution impact brand stigma; Society brand identification has media function that product harm crisis attribution impact brand stigma is not proved.

\section{LITERATURE REVIEW}

\section{A Stigma}

\section{a) Concept of Stigma}

Stigma refers to some kinds of skepticism about certain attributes. Specifically, stigma equals to the impression bad and lasting. From micro perspective, individual judgement would influence social judgement which is about some bad characteristics. From macro perspective, collective judgement would lead to stigma. According to different subject, scholars have made different definitions of stigma. Many social psychologists believe that stigma is a type of cognitive mechanisms of stereotypes and forms. However, sociologists believe that stigma is sources of pressure, which could influence someone suffering from stigma (Ahluwalia, 2000). Although scholars have different understanding of stigma, they have something in common. Firstly, in certain senses, stigma makes differences (Aiken, 1991). Secondly, stigma is always connected with stereotyping. Thirdly, stigma reflects the way how people treat the world. Lastly, no matter what causes stigma, the effect of stigma would not change.

Stigma is a multilevel phenomenon whereby social groups (macro level) form collective judgments about the consequences of bearing a particular stigma marking and whereby persons (micro level) who bear that marking are socialized to incorporate the judgments of the wider society into their conception of self (cf. Goffman, 1963).A stigma "refers to an attribute that is deeply discrediting" (Goffman 1963, 3). The stigmatized characteristic or trait labels the possessor as different from what is considered "normal" in some way. More specifically, in order for stigmatization to occur, the attribute in question must be connected with one or more negative stereotypes (Jones et al. 1984). Because stigma has often been an outcome rather than the basis of research in consumer behavior, researchers need to attain a better understanding of how stigmatization and consumption interact. A more in-depth analysis is needed to explore both how consumption cre- 
ates and perpetuates stereotypes, as well as how people utilize it to manage stigma.

In order for stigmatization to occur, the attribute in question must be connected with negative evaluations and stereotypes (Jones et al. 1984). There are many human differences that are not generally stigmatized, while other differences are routinely subjected to stigmatization. Only those attributes that are inconsistent with society's stereotype of what is "normal" are considered stigma.

Despite (or perhaps because of) the plethora of research on stigma, there is a lack of clarity in how stigma is defined. Many scholars researching stigma do not explicitly define the construct and fail to differentiate it from related constructs such as stereotypes (Link and Phelan 2001; Stafford and Scott 1986). Furthermore, depending on their discipline and what context they are studying, scholars treat the construct differently. For example, many social psychologists treat stigma as a cognitive mechanism through which to understand the process of stereotyping (e.g., Crocker et al. 1998), while sociologists treat stigma as a stressor to study how it affects stigmatized individuals (e.g., Link and Phelan 1999).

Although scholars have different understanding of stigma, they have something in common. Firstly, in certain senses, stigma makes differences (Aiken, 1991). Secondly, stigma is always connected with stereotyping. Thirdly, stigma reflects the way how people treat the world. Lastly, no matter what causes stigma, the effect of stigma would not change. There are a variety of theories regarding the social origins of stigma, but they are generally regarded as reflecting perceived threats to social order or survival or the outcome of one group's desire to subordinate another for economic power or other gains (Kurzban and Leary, 2001; Phelan et. al. 2009; Strangor and Crandall, 2000). However, it is important to note that despite general agreement regarding the origins of stigmas, there is a dearth of literature examining the historical evolution of stigmas, and researchers have identified this gap as problematic as such information is crucial to understanding both the ongoing social construction and disruption of stigmas and, relatedly, the most effective interventions (Hallgrimsdottir et. al. 2008; Phelan et. al, 2009).

Link and other scholars redefine the concept of stigma. They believe that five ingredients appear at the same time: First, people are clearly aware of human differences between who is under stigma and who is not; Second, the one who is under stigma is usually away from the mainstream culture; Third, the colony label is divided; Fourth, the one who is tagged usually suffers from discrimination, and the extent of the stigma is completely determined by the opposing social groups. As long as there is a credible group to admit the existence of stigma, the stigma will always exist. As a result, the stigma is actually a comprehensive phenomenon about labeling, stereotypes and loss of status (Lewicki, 1998). The definition clearly reflects the stigma phenomenon which will lead to the change of group status and social relations. Social culture will develop a strong role in the process of stigma formation and it's very difficult to reverse. This definition has been widely recognized (Lount, 2008).

Long and frequently studied as a social phenomenon, stigma is an underexposed theoretical construct in the marketing domain (Ellen \& Bone, 2008). Although the term "stigma" is often used colloquially in marketing to describe a product or person to whom a negative image has been ascribed (Wilson, 2005), relatively little has been written about stigmatization in the marketing literature. Few marketing-related studies focus almost exclusively on social stigma and the coping mechanisms of people who feel or fear stigma. Research has demonstrated that being stigmatized has significant negative consequences for a person and psychological marking of stigmas and their negative implications are still prevalent (Argo \& Main, 2008). However, stigma is not limited to just social stigma and marketing's almost exclusive focus on social stigma has ignored the broader context of stigma as recognized by other disciplines, where stigma is defined as "a mark placed on a person, place, technology, or product associated with a particular attribute that identifies it as different and deviant, flawed or undesirable" and results in elevated risk perceptions (Kasperson, Jhaveri, \& Kasperson, 2001). Although, marketing academics have studied other marks, such as COO labeling, which have been shown to systematically influence consumers' quality perceptions, yet to date the marketing literature has largely ignored the construct of stigma and its potential impact on consumers quality judgments, attitudes, and choice behavior in the marketplace. (Loebnitz, 2009)

There is not a great deal of research that explicitly examines stigma and stigma management in consumer research compared to other social science disciplines. In the majority of articles mentioning the construct, it remains relegated to the background and researchers often fail to unpack all of the components of stigma. Furthermore, the literature that does exist tends to be context specific. Yet, while there is a dearth of scholarship that explicitly investigates stigma in consumer research, the construct is implicitly prevalent throughout the literature. The following sections discuss stigma (Crosby, 2012)

\section{b) Strategy to Alleviate Stigma}

Summarizing current research about stigma formation mechanism, we have found that three ways can be utilized to reduce the stigma of mental health: protests, education, and contact. Protest strategy emphasizes the stigma that brings people's harm and pain. It suggests that people should condemn a stigma and advise people to take various measures to avoid the stigma which causes all kinds of injustice. Education strategy rise people's understanding about stigma. Contacting strategy allows people to feel and communicate, and feelings help avoid stigma.

Considering the severity of the potential negative outcomes of stigmatization, organizational leaders will attempt to defend the organization against emerging stigmatization threats (Ashforth and Gibbs, 1990; Suchman, 1995), i.e., to demonstrate to constituents that challenges are off-base or that the behaviors under scrutiny are anomalies or are being fixed. By defending itself against stigmatizing pressures, a firm attempts to mitigate damage to its reputation and derail momentum towards more severe consequences. Existing work on defensive actions has focused primarily on how firms use verbal accounts to manage stakeholder impressions (e.g., Carter, 2006; Elsbach, 1994; Elsbach and Sutton, 1992; Marcus and 
Goodman, 1991). However, impression management relating to organizational legitimacy 'extends well beyond traditional discourse to include a wide range of meaningladen actions and nonverbal displays' (Suchman, 1995). The adoption of a new practice, therefore, is a concrete way for an organization to show its intent to abide by field-level norms and help a firm achieve the primary objective of impression management: influencing the perceptions that different audiences have of an organization (Elsbach, 2006).

\section{c) Brand Stigma}

Just as individuals, brand also confronts the situation of stigma. The research about brand stigma is not popular at present. Mayhem (2002) hold an opinion that consumer would choose their self-image to suit brand impression. We are aware that the brand will be in the scope of purchase decision. For example, Volkswagen has a practical and economic identity token as it saves energy. They would choose Volkswagen cars as they think the brand has a good stigma of being practical and thrifty. These brands also reflects the brand consumption. In addition, similar to the individual characteristics, the attribute of a particular brand depends on the social situation and environmental factors. The user for the stereotype of a brand depends on his social class.

Aaker (1997) claims that the brand has a personality, and it is associated with human character of the brand. In some cases, these characteristics or attributes lead to a brand stigma. Consumer identity plays an important role in the study of stigma. Individuals often integrate themselves with cultural significance and make products become an extension part of their self-characteristics. In addition, people can show their identity in process of consumption (Vassilikopoulou, 2009).

Furthermore, similar to individual stigmatization, whether a particular brand attribute is stigmatized depends on situational and environmental factors. Munson and Spivey (1981) assert that the stereotypes of the users of a brand vary depending on social class. That is, stereotypes held by working- class consumers about a person driving a Ford automobile are different than those maintained by upper-class individuals (Crosby, 2012).

Brands face stigmatization on a variety of attributes. For example, country-of-origin (COO) stereotypes affect consumers' opinions of a brand (Peterson and Jolibert 1995). If a brand possesses French origins, it may be associated with French stereotypes, such as being "snobby." Furthermore, Liu and Johnson (2005) argue that the country of origin affects consumer perceptions of a brand even when marketers do not actively promote the COO. Other brand attributes are also stigmatized, including personality and product-related attributes.

Similar to brands, products also face stigmatization in the marketplace. Ellen and Bone (2008) find that many consumers regard genetically modified foods to be a health risk, even though there is no scientific evidence to support the belief. Additionally, consumers view these foods as deviant and form a negative opinion of them. (Crosby, 2012)

\section{B Brand Relationship}

Basically, brand relationship includes brand relationship norms and brand relationship commitment. Brand relationship norms refers to the induction of expectation which can satisfy consumers expect of the brand. Brand relationship norms could help guide consumers to make specific shopping. Brand relationship commitment refers to a kind of intention, which reflects the degree of ownership desire of consumers, and this commitment would help maintain the consumer brand confidence effectively (CROSS, 2012).

Social identity theory (Brewer 1991; Tajfel and Turner 1985) posits that in articulating their sense of self, people typically go beyond their personal identity to develop a social identity. They do so by identifying with or categorizing themselves in a contextual manner (Kramer 1991) as members of various social categories (e.g., gender, ethnicity, occupation, sports teams as well as other, more short-lived and transient groups).

The personal identification function is related to the fact that consumers can identify themselves with some brands and develop feelings of affinity towards them. In the literature on brand influence, a basic theory refers to the congruence between the consumer's behavior, his selfimage and the product image. This theory is based on the idea that individuals can enrich their self-image through the images of the brands they buy and use. In this way, the theory upholds that the greater the consistency between the brand image and the consumer's self-image, the better the consumer's evaluation of a brand and the greater his intention to buy it (Graeff, 1996; Hogg et al., 2000). (Del Rio, Vazquez and Iglesias, 2001)

The social identification function is based on the brand's ability to act as a communication instrument allowing the consumer manifesting the desire to be integrated or, on the contrary, to dissociate himself from the groups of individuals that make up his closest social environment (those people with whom he currently interacts or aspires to do so). Consumers interested in this function will positively value those brands that enjoy a good reputation among the groups with which they belong to or aspire to form part of (Long and Shiffman, 2000). (Del Rio, Vazquez and Iglesias, 2001)

\section{a) Brand Relationship Norms}

Brand relationship norms refers to consumers specific expect from the brand and the brand expect from the consumers. Brand is the relationship link among stakeholders, strangers and others. In other words, brand stakeholders and the relationship between them depends on brand performance.

Brand relationship norms can be divided into communal brand relationship norms and exchange brand relationship norms. The core differences between communal brand relationship norms and exchange brand relationship norms is the fact that communal brand relationship norms is interactive, while exchange brand relationship norms is rather isolated.

Communal brand relationship norms is formed between consumers and brand with a focus on mutual benefits. It requires some kinds of stable desire of willing to 
pay certain price. Under communal brand relationship norms model, the consumers are confident in brand, loyal to brand and maintains a high lasting connection strength.

Exchange brand relationship norms is formed between consumers and brand with a focus on consumer benefits. Consumers believe brand at some cost and has a low level confidence in brands. Exchange brand relationship norms aims to form a long-term relationship which is meant to exchange interests (CLARKE, 1993).

\section{b) Brand Relationship Commitment}

Brand relationship commitment is a way to connect consumers with brands. The price consumers willing to pay could reflect their brand relationship commitment. Brand relationship commitment is also a way to save relationship between consumers and brand.

Brand emotional commitment, brand action commitment and brand sustainable commitment can be used to measure brand relationship commitment. Similarly, brand relationship commitment could construct a basement of trust. Brand relationship commitment management consists of the strategies employed by the brand to cope with the individuals. People are engaged in brand relationship commitment in various ways. Some people may attempt to correct the undesirable attribute but these attempts may leave the individual vulnerable to brand. Others may attempt to master all connecting attributes by their brand. People can also attempt to control who knows about their commitment to brand (GERMANN, 2013).

\section{c) Attribution}

Attribution could be divided into ability attribution and morality attribution (MARK, 1992). Ability attribution means that failure is caused by lack of ability. Morality attribution means that failure is caused by lack of morality. In general, observers tend to explain the attribution with ability attribution in priority. Morality attribution refers to the behavior which can be traced back to the morality. Ability is essential to people who get their success, and people are constantly seeking information to improve their abilities, and are very sensible on how their ability is evaluated. Sometimes judging one's ability is a difficult task and it may take a lot of time in a slow process. From this perspective, morality attribution is a kind of important supplement for ability attribution. Stafford and Scott (1986) states that in individuals tend to make attributions for the matter in human relations field and the attribution results may lead some elements or characteristic unwelcome due to their breaking of the society norm and further grow into stigma. Brand can be personalized and establish a relation like the similar situation in human affairs (Aggarwal, 2004; Frournier, 1998). Therefore, the complete conditions for brand stigma can be summarized as product harm crisis attribution result in some brand quality breaking brand relations norm. That is, two factors interact together to conduct brand growing stigma after a product harm crisis. One is product harm crisis attribution, the other is brand relationship.

Product harm crisis attribution can be categorized as ability attribution and morality attribution. Ability attribution means in consumers' mind the product harm crisis is due to the company's insufficient abilities, which could make the brand product look good or bad. These abilities are the brand company's production, marketing, planning, execution and sales services ability. Morality attribution means in consumers' mind the product harm crisis is due to the company's moral problems, for example, the company is unwilling to make qualified product to the market under a society accepted moral standard. A precondition for morality attribution is that the consumers believe the company is capable of making qualified products but choose not to do so. Nassif (2013) believes morality attribution is an invisible attribution, that is, it can be felt only after a deep thinking. Sccot (2008) believes that morality attribution happens only after a very severe product harm crisis of which the ability attribution is not able to answer peoples' concerns and questions.

\section{Research Conceptual Model}

The paper utilizes brand relationship as a moderator variable, product harm crisis attribution as independent variables, brand identity as intervening variable, brand stigma as dependent variable. An intermediate variable "brand identity" is introduced in the conceptual model for the following two reasons. First, when product harm crisis happens, consumers would try to find what is behind the event or what the major causes are, then they will make ability or morality attribution in an intervened way with their already established brand identity. Second, it is reliable to use individual brand identity and social brand identity to measure brand stigma. Brand has adjusting effect on product harm crisis attribution. Different brand relationship norms and brand relationship commitment have different effects on product harm crisis.

Thus, via brand identity, through connecting elements and conditions interacted in brand relationship, we find brand stigma mechanism after a product harm crisis event. The research conceptual model can be summarized as following:

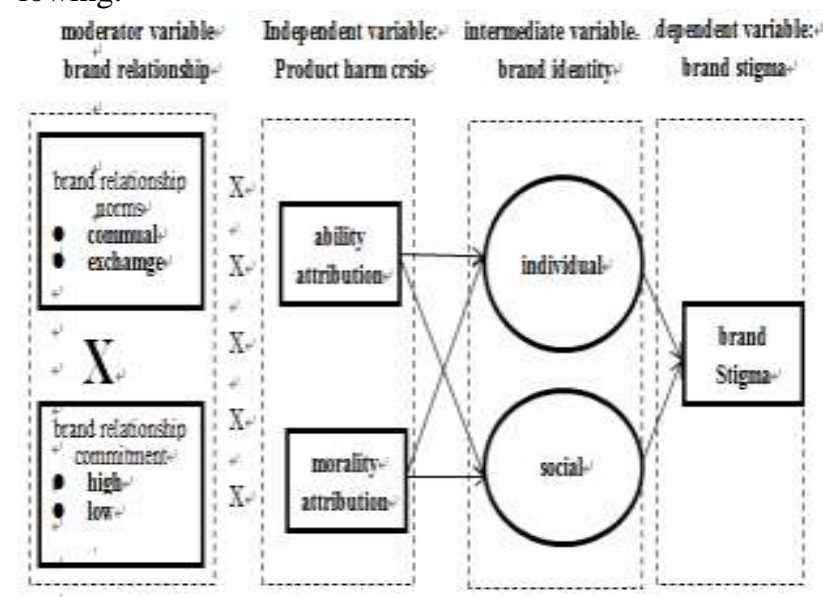

Figure 1. Research Conceptual Model

The paper makes the following hypothesis: (1) Compared to ability attribution, morality attribution could cause more serious brand stigma. (2) Brand relationship norms would adjust the influence of crisis attribution on brand stigma. Under the communal brand relationship norms, morality attribution is easier than ability attribution 
that cause brand stigma. (3) Under the exchange brand relationship norms, ability attribution is easier than morality attribution that cause brand stigma. (4) Brand relationship commitment could adjust the impact of product harm crisis on brand stigma. Under high level brand relationship commitment, morality attribution is easier than ability attribution that cause brand stigma. (5)Under low level brand relationship commitment, morality attribution is easier than ability attribution that cause brand stigma. (6)Crisis attribution, brand relationship norms and brand relationship commitment have triple interaction.

\section{REFERENCES}

[1] Aaker D A. Managing brand equity: Capitalizing on the value of a brand name[M]. Free press New York, 1991

[2] Bearden W O, Teel J E. Selected determinants of consumer satisfaction and complaint reports[J]. Journal of Marketing Research, 1983, 20(1): 21-28.

[3] Aaker, D.A. and K.L. Keller, Consumer evaluations of brand extensions. Journal of Marketing, 1990. 54(January): p. 27-41.

[4] Ahluwalia, R., R.E. Burnkrant and H.R. Unnava, Consumer response to negative publicity: The moderating role of commitment. Journal of Marketing Research, 2000. 37(2): p. 203-214.

[5] Ahluwalia, R., H.R. Unnava and R.E. Burnkrant, The moderating role of commitment on the spillover effect of marketing communications. Journal of Marketing Research, 2001. 38(4): p. 458-470.
[6] Aiken, L.S., S.G. West and R.R. Reno, Multiple regression: Testing and interpreting interactions. 1991, Newbury Park, CA: Sage Publications, Inc.research, 1994. 31(2): p. 214-228.

[7] Lewicki R J, Mcallister D J, Bies R J. Trust and distrust: New relationships and realities[J]. Academy of management Review, 1998, 23(3): 438-458.

[8] Lount R B, Zhong C, Sivanathan N, et al. Getting off on the wrong foot: The timing of a breach and the restoration of trust[J]. Personality and Social Psychology Bulletin, 2008, 34(12): 1601-1612.

[9] Maxham J G. Modeling customer perceptions of complaint handling over time: the effects of perceived justice on satisfaction and intent[J]. Journal of Retailing, 2002, 78(4): 239-252.

[10]Mayer R C, Davis J H, Schoorman F D. An integrative model of organizational trust [J]. Academy of management review, 1995, 20(3): 709-734.

[11]Vassilikopoulou A, Siomkos G, Chatzipanagiotou K, et al. Productharm crisis management: Time heals all wounds? [J]. Journal of Retailing and Consumer Services, 2009, 16(3): 174-180.

[12]L. CROSS. Customer Intimacy: the Bonds that Go Beyond [J] Graphics Arts Monthly, 2012.

[13]M. CLARKE. The effect of advertising on brand awareness and perceived quality: An empirical investigation using panel data $[\mathrm{J}]$ Quantitative Marketing \& Economics, 1993.

[14]F. GERMANN. Product recalls and the moderating role of brand commitment [J] Marketing letters, 2013.

[15]B. MARK. Relationships in Marketing: a Review of the Implications of Agency and Related Theories [J] Journal of Market, 1992. 